\title{
The evaluation of effects of lornoxicam on blood flow and erythrocyte deformability in comparison with iv paracetamol in rats
}

\author{
Arslan $\mathrm{M}^{1}$, Comu FM르, Isik B ${ }^{1}$, Atac $\mathrm{MS}^{1}$, Yilmaz D ${ }^{1}$ \\ Department of Oral and Maxillofacial Surgery, Gazi University Faculty of Dentistry, Ankara, Turkey. \\ mustarslan@gmail.com
}

\begin{abstract}
Background: Lornoxicam and iv paracetamol are commonly preferred to be used for postoperative analgesia. Although Aspirin is a well known non-steroid anti-inflammatory drug that decreases the erythrocyte deformability, there is no study comparing lornoxicam and iv paracetamol regarding their effects on erythrocyte deformability recorded in literature. The aim of this study was to compare the effects of lornoxicam and IV paracetamol on blood perfusion and erythrocyte deformability on rats.

Methods: Twenty male Wistar Albino rats were randomly divided into three groups as Lornoxicam group (Group L), IV paracetamol group (Group P), and control group (Group C). Intraperitoneal administrations were done in all groups except Group C. Liver and renal blood flows were conducted by laser Doppler and euthanasia was performed via intraabdominal blood uptake. Erythrocyte deformability was measured using a constant flow filtrometer system. Results: Lornoxicam increased the relative resistance which shows the erythrocyte deformability in rats $(p<0.05)$. The comparison of Groups $C$ and $P$ revealed no statistically different results $(p=0.731)$ while Group $L$ revealed statistically higher results than Group C $(p=0.022)$. No statistically significant differences were found between groups $L$ and $P(p=0.073)$. Liver and renal blood flow values in Group $L$ were just numerically decreased not statistically whilst no statistically significant difference was found between the three groups.

Conclusions: Lornoxicam have lead to functional disorders related to tissue perfusion as a result of both decreased blood flow and erythrocyte deformability (Fig. 3, Ref. 21). Full Text in PDF www.elis.sk.

Key words: rat, lornoxicam, iv paracetamol, erythrocyte deformability, blood flow.
\end{abstract}

For migration of oxygen and vital molecules to the final organ capillaries and clearance of metabolic wastes, erythrocytes must be able to extend and curve and have the capability to move in these areas. This capacity is referred to as deformability. Erythrocyte deformability and plasma viscosity are important factors that affect organ and tissue perfusion (1-3). The protection of tissue perfusion is especially essential in postoperative period due to its effects on wound healing. ${ }^{4}$

Protection of tissue perfusion is highly essential for wound healing therefore it becomes more important (4). It has been shown that postoperative administration of aspirin has decreased the erythrocyte deformability more than dipyrone, ibuprofen, or ketorolac (5).

Beside its inhibitory effects on cyclooxygenase (COX) I and II in peripheral receptors, lornoxicam also increases prostaglandin, endogenous dinorphin and beta-endorphin levels promoting central analgesic and anti inflammatory effects $(6,7)$. Intravenous paracetamol is accepted and preferred as a drug for its selective

${ }^{1}$ Department of Oral and Maxillofacial Surgery, Gazi University Faculty of Dentistry, Ankara, Turkey, and ${ }^{2}$ Department of Physiology, Kirikkale University Faculty of Medicine, Kirikkale, Turkey

Address for correspondence: M. Arslan, MD, Gazi University Faculty of Dentistry, Anesthesiology and Reanimation Specialist, Department of Oral and Maxillofacial Surgery, Emek 06510Ankara, Turkey.

Phone: +90.312 .2034335$ inhibition effect on COX of central nervous system $(8,9)$. Till today we have not seen a comparative study of lornoxicam and IV paracetamol on the erythrocyte deformability which has a role in tissue perfusion.

This experimental study is aimed to evaluate the effects of lornoxicam on blood flow and erythrocyte deformability in comparison with iv paracetamol in rats.

\section{Methods}

This study was conducted in the Physiology Laboratory of Kirikkale University upon consent of the Experimental Animals Ethics Committee of Kirikkale University.

In the study, 20 male Wistar Albino rats, 275-350 gr in weight, raised under equal enviromental conditions, were used.The rats were kept at $20-21{ }^{\circ} \mathrm{C}$, at cycles of 12 -hour daylight and 12-hour darkness and had free access to food until 2 hours before the anesthesia procedure.

Three groups of rats were formed for the study. Randomized 6 rats were grouped as control and no surgical procedure was performed (Group $\mathrm{C}, \mathrm{n}=6$ ). One study group was administered lornoxicam (Xefo ${ }^{\circledR}$ Abi Ibrahim Ilaç San ve Tic A.S, Istanbul, Turkey) $1.3 \mathrm{mg} \mathrm{kg}^{-1}$ intraperitoneally (Group L) and the other study group was administered iv paracetamol (Perfalgan ${ }^{\circledR}$ Bristol-Myers Squibb Pharmaceuticals Ltd, UK) $100 \mathrm{mg} \mathrm{kg}^{-1}$ intraperitoneally (Group P). 
$211-213$

Thirty minutes after lornoxicam and iv paracetamol administration, the rats were weighed and then anaesthetized with ketamine $\left(\operatorname{Ketalar}^{\circledR} 50 \mathrm{mg} \mathrm{mL}^{-1}\right.$, Pfizer, Istanbul, Turkey), and euthanasia was performed via intraabdominal blood uptake. Heparinized total blood samples were used to prepare erythrocyte packs. Deformability measurements were done by erythrocyte suspensions with $5 \%$ htc in phosphate-buffered saline (PBS) buffer.

\section{Liver and renal blood flow measurement}

Liver and renal blood flows were recorded. Blood flow measurements were conducted by placing and fixing the probe on the tissue by a laser Doppler microvascular perfusion monitor (OxyLab LDF; Oxford Optronix Limited, Oxford, UK).

\section{Deformability measurements}

Erythrocyte deformability was measured using a constant flow filtrometer system (MP 30, Biopac Systems Inc, Commat, USA). Erythrocyte suspension that was delivered at $1 \mathrm{ml} / \mathrm{min}$ flow rate was passed through a nucleopor-polycarbonate filter of $5 \mu \mathrm{m}$ in diameter, and alterations in filtration pressure corresponding to different flow rates were measured. The pressure alterations were transferred to computer medium with an MP 30 data equation system. The ratio of filtration pressure values for cellular suspension and buffer were calculated, as well as the relative resistance.

\section{Statistical mnalysis}

Statistical Package for Social Sciences (SPSS, Chicago, IL, USA) 12.0 program was used for statistical analysis. Erythrocyte deformability, liver and renal blood flow of study groups were assessed by using Kruskal-Wallis test. Bonferroni adjusted MannWhitney U test was used after significant Kruskal-Wallis to determine which group differs from the other. Results were expressed as mean \pm standard deviation (Mean $\pm \mathrm{SD}$ ). Statistical significance was set at a $p$ value $<0.05$ for all analysis and $p<0.033(0.1 / 3)$ for Bonferroni adjusted Mann-Whitney U

\section{Results}

The results of the study indicated that lornoxicam increased the relative resistance, a marker of erythrocyte deformability of rats ( $p<0.05)$ (Fig.1). There were significant differences between the groups according to the comparisons with Kruskal-Wallis test $(\mathrm{p}=0.048)$. The results obtained after corrections with Mann Whitney U test were as follows: Comparisons of groups $\mathrm{C}$ and Prevelaed similar results $(\mathrm{p}=0.731)$. The values of rats in group L were significantly higher than those of the rats in group $\mathrm{C}(\mathrm{p}=0.022)$. No statistically significant differences were found between groups $\mathrm{L}$ and $\mathrm{P}(\mathrm{p}=0.073)$.

When compared with group $\mathrm{C}$, the liver and renal blood flows in group L were numerically lower where the group $\mathrm{P}$ was similar (Figs 2 and Fig 3, respectively).

\section{Discussion}

The blood flow through the tissue, viscosity of the blood and erythrocyte deformability is the most important factors that affect

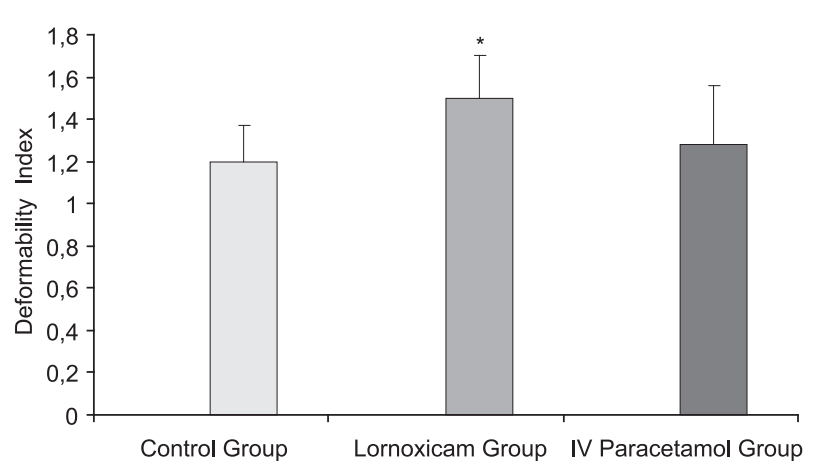

Fig. 1. Erythrocyte deformability values in the groups. * $p<0.05$ compared to the Control Group.

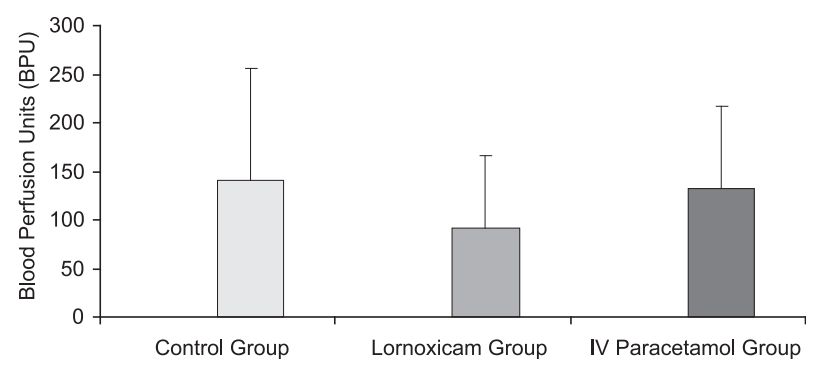

Fig. 2. Distributions of Liver Blood Flow Measurements in Blood Perfusion Units (BPU). * $\mathbf{p}<\mathbf{0 . 0 5}$ compared to the Control Group.

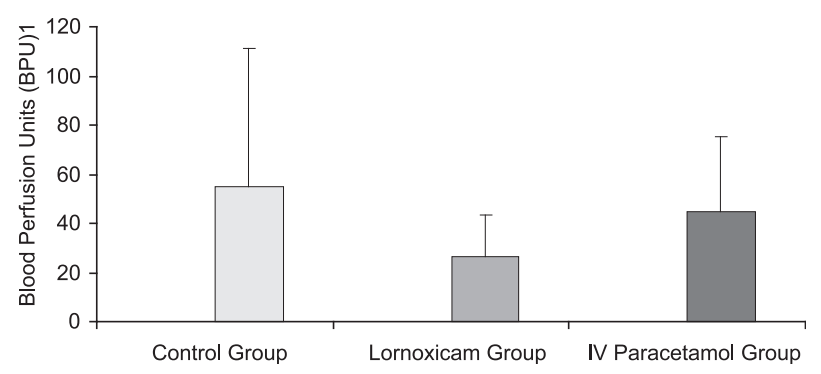

Fig. 3. Distributions of Renal Blood Flow Measurements in Blood Perfusion Units (BPU). * $\mathbf{p}<\mathbf{0 . 0 5}$ compared to the Control Group.

the tissue perfusion. It has been reported that changes like decrease in erythrocyte deformability and increase in blood viscosity; are seen after surgeries performed under general anesthesia $(2,10)$.

The erythrocyte deformability affects plasma viscosity and perfusion of organs and tissue. For aiding the migration of oxygen and vital molecules to final organ capillaries, and clearance of metabolic wastes, erythrocytes must be able to extend and curve and have the capability to move in these areas $(3,11)$. This study revealed that i.p. administration of lornoxicam in rats decreased the erythrocyte deformability.

The erythrocyte deformability method used in this study is composed of hole of similar size to those in the capillary system, and thus it is a reliable experimental model for microcirculation and an increase in erythrocyte deformability index is a sign of reduced erythrocyte deformability (12). In the current study, in lornoxicam group, the erythrocyte deformability index was found to be high.

The dosage of drug is important for evaluating their clinical effectiveness as well as their side effects. Even though a lot of com- 
parative studies related to lornoxicam can be found, no concessions regarding its therapeutic dosage and toxicity is found. In their comparative study aimed at comparison of analgesic effect of lornoxicam $\left(1.3 \mathrm{mg} \mathrm{kg}^{-1}\right)$, piroxicam $\left(1.0 \mathrm{mg} \mathrm{kg}^{-1}\right)$ and meloxicam $(5.8 \mathrm{mg}$ $\mathrm{kg}^{-1}$ ) Bianchi and Panarei (14) found out that lornoxicam, piroxicam, and meloxicam produced the same anti-inflammatory effect, did not modify thermal nociceptive thresholds, and significantly reduced the hyperalgesia in rats. However, only lornoxicam was fully effective in preventing hyperalgesia. Similarly, Besson(15) showed that lowdose therapy with lornoxicam $\left(0.3 \mathrm{mg} \mathrm{kg}^{-1}\right)$ results in a strong reduction in nociceptive inflammatory processing. Similarly, Sen et al (16) reported that $1.3 \mathrm{mg} \mathrm{kg-1}$ dose of lornoxicam with the use of nitroglycerine provided early and efficient analgesia, but the increasing dose of lornoxicam $\left(2.6 \mathrm{mg} \mathrm{kg}^{-1}\right)$ did not maintain better analgesia.

It has been reported that the antinociceptive action of high $\left(400 \mathrm{mg} \mathrm{kg}^{-1}\right)$ and low dose $\left(100 \mathrm{mg} \mathrm{kg}^{-1}\right)$ of acetaminophen is antagonized by naloxone, which is a nonselective opioid receptor antagonist, and that the antinociceptive action caused by morphine is potentiated with low dose of acetaminophen while this effect is dependent upon the interaction between opioidergic and serotoninergic systems $(17,18)$. Sandrini et al $(18)$ administered morphine $\left(2,3\right.$, or $5 \mathrm{mg} \mathrm{kg}^{-1}$ subcutaneous) and acetaminophen (50 or 100 $\mathrm{mg} \mathrm{kg}^{-1}$ i.p.) to male Wistar rats that were pretreated with naloxone ( $1 \mathrm{mg} \mathrm{kg}^{-1}$ i.p.) in their study. As a result, they found out that the enhancement in antinociceptive action made by $100 \mathrm{mg} \mathrm{kg}^{-1}$ acetaminophen was blocked by naloxone. In their study, Madenoglu et al (19) showed that opioid receptors were blocked with naloxone and then with acetaminophen which was administered at a dose of $300 \mathrm{mg} \mathrm{kg}^{-1}$. Sawadogo et al (20) showed in a mouse study that $100 \mathrm{mg} \mathrm{kg}^{-1}$ administration of paracetamol had an analgesic effect.

In the current study, i.p. administration of lornoxicam (Xefo) 1.3 $\mathrm{mg} \mathrm{kg}^{-1}$ and paracetamol (Perfalgan) $100 \mathrm{mg} \mathrm{kg}^{-1}$ was performed.

Non-steroidal anti-inflammatory drug (NSAID) may cause to reduce the renal blood flow, glomerularfiltration rate, retention of water and sodium and may also cause hyperkalemia (21) the administration of single dose of lornoxicam on rats in our study, revealed that liver and renal blood flow was decreased but this was not statistically significant. On the other hand iv paracetamol did not cause any alterations.

NSAIDs may cause erythrocyte deformability. Bozzo et al (15) indicated in their study that, aspirin showed the most remarkable effects on erythrocyte deformability, closely followed by dipyrone. The effects of ketorolac were moderate, whereas ibuprofen had a minor impact on platelet function. In our study we also find out that lornoxicam may reduce the erythrocyte deformability.

In conclusion we believe that administration of lornoxicam my cause functional disorders for tissue perfusion by decreasing both the blood flow and erythrocyte deformability. We also suggest that our results should be supported by clinical and experimental studies with larger series.

\section{References}

1. Simchon S, Jank M, Chien S. Influence of reduced red cell deformability on regional blood flow. Am J Physiol 1987; 22: 898-903.

2. Muller R, Musikic P. Hemorheology in surgery:a review. Angiology 1987; 38: 581-592.
3. Zinchuk VV. Erythrocyte deformability: physiological aspects. Usp Fiziol Nauk 2001; 32: 66-78.

4. Nuutinen LS, Laitinen JO, Salomaki TE. A risk-benefit appraisal of injectable NSAIDs in the management of postoperative pain. Drug Saf 1993; 9: 380-393.

5. Bozzo J, Escolar G, Hernández MR, Galán AM, Ordinas A. Prohemorrhagic Potential of Dipyrone, Ibuprofen, Ketorolac, and Aspirin: Mechanisms Associated with Blood Flow and Erythrocyte Deformability. J Cardiovasc Pharmacol 2001; 38: 183-190.

6. Arslan M, Tuncer B, Babacan A, Taneri F, Karadenizli Y, Onuk E, Ege B. Postoperative analgesic effects of lornoxicam after thyroidectomy: A placebo controlled randomized study. Agri 2006;18: 27-33.

7. Beilin B, Besler H, Mayburd E, Smirnov G, Dekel A, Yardeni I, Shavit $Y$. Effects of preemptive analgesia on pain and cytokine production in the postoperative period. Anesthesiology 2003; 98: 151-155.

8. Bonnefont J, Courade JP, Alloui A, Eschalier A. Antinociceptive mechanism of action of paracetamol. Drugs 2003; 63: 1-4.

9. Pini LA, Vitale G, OttaniA, Sandrini M. Naloxone-reversible antinociception by paracetamol in the rat. J Pharmacol Exp Therapeut 1997; 280: 934-940.

10. Dormandy JA. Effects of anaesthesia and surgery on the flow properties of blood. Microcirc Endothelium Lymphatics 1984; 1: 151-168.

11. Weed RI, Chaillyey B. Calcium pH interactions in the production of shape change in erythrocytes. 58-68. In: Red Cell Shape. Berlin, Heidelberg, New York: Springer-Verlag, 1972.

12. Arslan M, Comu FM, Isik B, Unal Y, Cekmen N, Kurtipek O. Effects of a general anaesthetic agent, propofol, on erythrocyte deformability. Bratisl Med J 2010; 111: 126-128.

13. Skjodt NM, Davies NM. Clinical pharmacokinetics of lornoxicam. A short half-life oxicam. Clin Pharmacokinet 1998; 34: 421-428.

14. Bianchi M, Panerai AE. Effects of lornoxicam, piroxicam, and meloxicam in a model of thermal hindpaw hyperalgesia induced by formalin injection in rat tail. Pharmacol Res 2002; 45: 101-105.

15. Buritova $\mathbf{J}$ and Besson $M$. Dose-related anti-inflammatory/analgesic effects of lornoxicam: A spinal c-Fos protein study in the rat. Inflamm Res 1998; 47: 18-25.

16. Sen S, Dost T, Aydin ON, Ogurlu M, Temucin S, Gursoy F. The effects of combination of two lornoxicam doses and nitroglycerine on acute pain in rat. Agri 2005;17: 47-52.

17. Bujalska M. Effect of nonselective and selective opioid receptors antagonists on antinociceptive action of acetaminophen (part III). Pol J Pharmacol 2004; 56: 539-545.

18. Sandrini M, Vitale G, Ottani A, Pini LA. The potentiation of analgesic activity of paracetamol plus morphine involves the serotonergic system in rat brain. Inflamm Res 1999; 48: 120-127.

19. Madenoglu H, Kaçmaz M, Aksu R, et al. Effects of Naloxone and Flumazenil on AntinociceptiveAction of Acetaminophen in Rats. Curr Ther Res Clin Exp 2010; 71: 111-117.

20. Sawadogo WR, Boly R, Lompo M, et al. Anti-inflammatory, analgesic and antipyretic activities of Dicliptera verticillata. International Journal of Pharmacology 2006; 2: 435-438.

21. Gambaro G, Perazella MA. Adverse renal effects of antiinflammatory agents: evaluation of selective and nonselective cyclooxygenase inhibitors. J Int Med 2003; 253: 643-652.

Received June 27, 2011. Accepted January 13, 2012. 